\title{
Patterns of Inequalities in Public Transfers by Gender in China ${ }^{1}$
}

\author{
Ke SHEN ${ }^{\mathrm{a}^{*}}$, WANG Feng ${ }^{\mathrm{a}, \mathrm{b}}$, Yong CAI ${ }^{\mathrm{c}}$ \\ ${ }^{a}$ School of Social Development and Public Policy, Fudan University, 200433, China \\ ${ }^{\mathrm{b}}$ Department of Sociology, University of California, Irvine, CA 92697, USA \\ ${ }^{\mathrm{c}}$ Department of Sociology, University of North Carolina, Chapel Hill, NC 27599, USA
}

* Corresponding author. Room 908, Wen Ke Building, Fudan University, No. 220 Handan

Road, 200433, Shanghai, China. Email: shenke@fudan.edu.cn

\footnotetext{
${ }^{1}$ This study is supported by Statistics Korea, East-West Center, Shanghai Planning Project of Philosophy and Social Science (2012ESH001), and Shanghai Educational Committee (14ZS005), and the National Science Foundation of China $(71273059,71461137003,71490734)$. Early version of the paper was presented at the EWC-KOSTAT Conference on "The Demographic Dividend and Population Aging in Asia and the Pacific", East-West Center, Honolulu, October 29-30, 2015. We would like to thank Sang-Hyop Lee for his tremendous help in setting up NTA calculations for China, and Ronald Lee, Andrew Mason, J.M. Ian Salas and other conference participants for their insightful comments and suggestions. We are also grateful to two anonymous reviewers and the editor for their constructive comments and suggestions.
} 


\title{
Patterns of Inequalities in Public Transfers by Gender in China
}

\begin{abstract}
This paper offers an empirical examination of gender inequality in China based on public transfers in education, health care and pension benefits over the lifecycle. Using data from the 2010 wave of China Family Panel Studies and administrative records, we apply the internationally comparable method of National Transfer Accounts to estimate incidences and patterns of public transfers by gender. Our results show that, while public health care and pension transfers are remarkably biased against women at old ages, public education transfers are essentially gender-neutral even at the tertiary education level. Gender inequality among older cohorts is largely a legacy of past occupational and earning privileges for males, and the fragmented design of China's health insurance and pension programs. With increasing female advantage in education and a gradual unification of China's social security system, gender gaps in public transfers in China are likely to narrow, though by no means disappear, in the coming years.
\end{abstract}

Keywords: Public Transfer; Gender Inequality; China 


\section{Introduction}

Across all regions of the world, governments and international organizations have placed achieving gender equality as a top political goal. Gender equality for instance is one of UNESCO's two global priorities. It is the third goal under Millennium Development Goals of the United Nations, and one of the seven Basic State Policies in China. ${ }^{2}$ Gender gaps in economic and political life nevertheless remain prevalent in most societies, even in social democratic states, which have the best records of achieving and maintaining gender equality. In Denmark, for instance, women's average hourly wage was $82 \%$ of men's, $76 \%$ in UK, and merely $49 \%$ in Japan in 2006 (Chang and England 2011). Gender inequality not only deprives women of their autonomy (Sen 1999), but also adversely affects social, political and economic functioning of the whole society, such as increased child mortality, ineffective governance, and reduced economic growth (Branisa and Klasen 2013, Klasen and Lamanna 2009). In different parts of the world, gendered affirmative action measures have also been introduced to achieve gender equality. Such measures include electoral gender quotas to enhance female representation in politics, and parental and paternity leave policies to encourage participation of fathers in child care and of mothers in the labor market (Borrell et al. 2014, Evertsson et al. 2009).

In an area where government policies can often have the most immediate effect on social inequality, namely in public transfers, however, gender has not always been taken as an explicit consideration. Public transfers include both in-kind transfers such as public education and health care (goods and services directly provided by the government), and cash transfers such as pension (direct transfer payment to intended beneficiaries). Policies of public transfers are mostly designed to fight poverty and to improve overall equity through resource redistribution (Castro-Leal et al. 1999). These transfers are often designed on the basis of income groups, such as social protection and educational vouchers for the poor, or on the basis of age, such as Medicare for the aged and public pensions (Folbre and Wolf 2012, Kotlikoff and Burns 2012, Lee 2012, Lee and Mason 2011). Much less commonly seen are public transfer programs that are specifically designed to redistribute resources on the basis

\footnotetext{
${ }^{2}$ Other Basic State Policies in China include family planning policy, environmental protection, conservation of water and soil.
} 
of gender.

Given the pervasive gender gaps in most countries, seemingly gender-blind public transfer programs designed for other purposes may have intended or unintended gendered consequences (Earles 2013, Ginn and MacIntyre 2013). Gender differentials in school enrolment, employment, occupation and health, for instance, can lead to gender-biased incidence of public education, health care and pension transfers, which in turn ameliorate or exacerbate the existing gender gaps. To the best of our knowledge, gender inequality in public transfers has not been examined explicitly, except for limited research on gender gap in public pensions (Ginn and MacIntyre 2013, Takayama 2014).

China offers a rare and fascinating economic and institutional context to investigate the pattern of gender inequality in public transfers. On one hand, China still embraces huge gender gaps, particularly at infanthood and at advanced ages, which might be the legacy of traditional son preference and a gender hierarchy within and outside the family, as discussed in the second section later in this paper. On the other hand, public education, health care and pension programs have undergone dramatic expansions and transformations over the past decade, made possible by China's hyper economic growth and its explosive increase in government revenue. A comprehensive examination of the gendered implications of public transfer programs help evaluate these policy shifts and lay a foundation for future reforms in China as well as in other developing countries.

Drawing on the rich information obtained with the methodology of National Transfer Accounts, we examine gender differentials in three major types of public transfers over the lifecycle. Two questions are addressed. The first and the basic question is whether public education, health care and pension spending is equally allocated to men and women. The second and related question is whether gender inequality in public transfers varies by age groups. We are interested in examining, in other words, whether gender inequality in public transfers is less severe for younger cohorts in comparison to older cohorts, a finding that bears long-term social implications.

The remainder of this paper is structured as follows. Section 2 offers a general background of gender inequality and recent changes in public transfer programs in China. Section 3 introduces the methodology and data used for this study. Section 4 
presents the main results of our analyses. Section 5 discusses our results and the implications of our study for gender equality in China in the future.

\section{Changing Contexts of Gender Inequality and Public Transfers}

\subsection{Changing patterns of China's gender inequality}

China's hyper economic growth over the last three decades has taken place at the same time as a number of radical socioeconomic and demographic transitions have unfolded. These transformations include a rapid increase in employment in the private sector, restructuring of state-owned enterprises, a massive process of migration and urbanization, vast expansion in higher educational institutions, and a continued decline in fertility (Shu and Bian 2003, Wang 2011, Zhang and Hannum 2015). These transitions have generated unprecedented and unequal opportunities for both men and women, yielding a complex set of changes in gender relations.

Unlike most other societies, China's gender inequality emerges at the very beginning of life. The adoption of one-child policy since 1980 combined with strong son preference pushed sex ratio at birth in China to deviate from the biologically normal range of 103-106 (Coale and Banister 1994). ${ }^{3}$ Sex ratio at birth in China jumped from 107.6 in 1982 to 116.9 in 2000 and further to 118.1 in 2010 (Cai 2013). Sex ratio of children aged 0-4 in 2010 stood at the high of 119.1. Imbalanced sex ratio under age 5 is directly caused by sex-selective abortions, underreporting of female births, and also female infanticide (Chu 2001, Hull 1990, Peng and Huang 1999, Zeng et al. 1993).

Gendered pattern of labor force participation has also undergone profound changes in China's post-reform period, since the late 1970s. As shown in Figure 1, over the past two decades, labor force participation rates at ages 15-24 dropped dramatically for both male and female, mainly due to a rapid expansion in college enrollment (elaborated in the next section). Female labor force participation at prime working ages (25-49), moreover, declined at a much faster pace than that of males. As the market-oriented reform deepened since the early 1990s, the power of the state has eroded both as an employer and as an advocate of women's rights, leading to discrimination against female workers in hiring and layoffs and thus potentially

\footnotetext{
${ }^{3}$ Sex ratio at birth: male live births per 100 female live births.
} 
enlarging the gender gap in labor force participation (Bian 2002; Honig and Hershatter 1988, Li and Li 2008, Yao and Tan 2005). We also notice that women started to withdraw from the labor market in a significant volume about 10 years earlier than men, around age 50 versus 60 , due to women's earlier retirement. In urban sector, legal retirement age for males is set at age 60, whereas it is set at age 50 for female factory workers and 55 for female government employees and state enterprise executives.

\section{[Figure 1 about here]}

Gender inequality is not only reflected in labor force participation, but more importantly in employment sectors and occupational categories, which in the context of China are directly linked to eligibility for public health insurance and pension benefits. As shown in Figure 2, between 1987 and 2010, there has been a sharp drop in the share of the labor force engaged in farming among young cohorts for both men and women. However, the gender gap did not narrow. ${ }^{4}$ A larger share of female labor force were engaged in farming than that of males in both time points, and the gap actually widened with the increase of age by 2010 . In non-farming sectors, while female labor force participation was very high during the socialist planned economy years (Bauer et al. 1992, Croll 1983), women were more heavily concentrated in the collective sector, which offered significantly lower wages and fringe benefits (health care, pension and housing) than the state sector (Shu and Bian 2003, Wang 2008, Whyte 1984). In 1980, merely $30.8 \%$ of workers in the state sector were women, in contrast to one half in the collective ownership sector. ${ }^{5}$ In the arena of political governance, women are still rarely seen and severely underrepresented. For example, only less than $15 \%$ of government organization and state enterprise heads were females in 1987 . This share increased to $25 \%$ in 2010 , with a slightly higher share among the heads aged in their 30s, at approximately the level of $30 \%$ in $2010{ }^{6}$

[Figure 2 about here]

The arrival of the capitalist market economy has also been accompanied by a prevalent commodification of women's bodies (Farrer 2014, Otis 2009, Parish et al. 2007). The gender hierarchy within the family is still deeply rooted in Chinese society as in other East Asian countries, in spite of a growing feminist awareness. Whereas

\footnotetext{
${ }^{4}$ Data source: China Statistical Yearbook 1987 and 2010 census.

${ }^{5}$ Data source: China Statistical Yearbook 1982.

${ }^{6}$ Data source: China Statistical Yearbook 1987 and 2010 census.
} 
the average weekly hours worked do not differ that much between women and men (44.9 versus 49.0 hours per week, according to China's 2008 Time Use Survey), women still spend twice as much time as men on average, 20.6 versus 9.5 hours per week, on unpaid household work. Women's domestic burden and care responsibility, in turn, give rise to a wage penalty at the workplace (Cohen and Wang 2009; Qi and Dong 2015).

These selected facts portray a picture of persistent gender inequality in China, particularly at infanthood as indicated by imbalanced sex ratio, and at advanced ages as shown by women's earlier retirement, higher share of labor force in farming, and severe underrepresentation in important political positions. At the same time, we also take note of a number of positive changes that have occurred: female youths are more likely to continue with education, leave the farming sector, and be promoted to leaders in government and enterprises than twenty years ago.

\subsection{Recent reforms in public transfer programs}

China's state-led economic growth has led to an explosive increase in government revenue, which has grown at an annual rate roughly twice the GDP growth rate for nearly two decades. With increased fiscal power and heightened concerns over social inequality, the Chinese government has drastically expanded public transfer programs in education, health care and pension. Between 1993 and 2013, public spending in education outpaced the rate of economic growth, with its share of GDP rising from $1.9 \%$ to $3.7 \%$. Public health care expenditure as a share of GDP rose slightly from $0.77 \%$ in 1993 to $0.82 \%$ in 2003 , and then doubled to $1.69 \%$ by $2013 .^{7}$

One of the most noticeable changes in public spending is in higher education expansion. In 1999, China's State Council approved a "Plan of Revitalizing Education in the Twenty-First Century," proposed by the Ministry of Education to expand college enrollment (Yeung 2013). The program aimed at improving human capital, alleviating urban unemployment, and driving economic growth (Treiman 2013, Wu 2010). College annual enrollment rose sharply subsequently, from 1 million in 1998 to 6.3 million in 2009 , and to over 7 million by 2014. Gross tertiary education

\footnotetext{
${ }^{7}$ Data source: China Health and Family Planning Statistical Yearbook 2015.
} 
enrollment ratio more than tripled, from $10.5 \%$ in 1998 to $37.5 \%$ in $2014 .{ }^{8}$ Of particular note has been a more dramatic increase in female enrollment than male enrollment. Female share of college students increased from 38\% in 1998 to $52 \%$ by 2013. ${ }^{9}$ As indicated by Figure 3, back in 2000, men were more likely to attend and to graduate from college than women for all age groups. In only one-decade time, gender gap for cohorts aged below 30 closed significantly. Nearly $30 \%$ of female youths in early 20s attended college by 2010 , outpacing the share for males at the same age.

[Figure 3 about here]

Parallel to increasing opportunities at the tertiary education level, mandatory public funding for nine-year compulsory education has also increased since 2001. By 2005, about one-third of students at compulsory education ages in western and central rural areas were waived of tuitions fees and received free textbooks. This program reached all rural students by 2007 and was extended to cover all urban students by 2008. With all of these endeavors, primary school education has achieved full coverage since the early 1990s and enrollment rate in lower middle schools rose from $88.7 \%$ in 2001 to $100 \%$ by $2010 .^{10}$

\footnotetext{
${ }^{8}$ Data source: China Educational Statistics Yearbook 2013.

${ }^{9}$ Data source: China Educational Statistics Yearbook 2013.

${ }^{10}$ Data source: China Educational Statistical Yearbook 2012.
} 
China's government has also made impressive progress in expanding public health insurance and pension coverage over the past ten years, especially to the rural population. Due to decades-long urban-rural segregation by hukou institution and urban-priority development strategy, nearly $80 \%$ of rural residents lacked health insurance before 2003 (Wagstaff et al. 2009), and over 90\% of rural elderly did not have any pension in 2007 (Shen and Williamson 2010). In 2003, the government launched the New Cooperative Medical Scheme (NCMS) in rural areas, which spread at an extraordinary speed and benefited $96 \%$ of rural residents by 2010 . New Rural Pension Scheme (NRPS) was first piloted in 320 rural counties (about $16 \%$ of total) in 2009 , then expanded to 838 counties in 2010 , and covered nearly all rural counties by 2012 (Cheng et al. 2015b). The rural insured are eligible for pension at the age of 60 . Monthly pension benefit is comprised of a flat basic pension payout at $55 \mathrm{RMB}$, subsidized by government and certain amount from individual pension account. ${ }^{11}$

Despite these progresses in establishing a universal social safety net, both public health insurance and pension system remain highly fragmented in China, varying by urban-rural residence and employment type (Lin et al. 2009, Liu and Zhao 2014, Pozen 2013). As noted, rural residents are participating in the New Cooperative Medical Scheme and the New Rural Pension Scheme. Urban residents without formal employment, including children, students, the self-employed and unemployed, are covered under the Urban Resident Basic Medical Insurance (URBMI) and Urban Resident Pension Scheme (URPS). ${ }^{12}$ Urban enterprise workers are entitled to Urban Employee Basic Medical Insurance (UEBMI) and Urban Enterprise Pension Scheme (UEPS). Civil servants, about 40 million, are enrolled in separate health insurance and pension scheme. Deductibles, reimbursement and a variety of covered services under the health insurance schemes for urban formal workers, particularly for civil servants, are much more generous than those for the rural population and unemployed urban residents. For example, inpatient reimbursement rate stood at $68.2 \%$ for UEBMI on average in 2010, in contrast to only $47.9 \%$ for URBMI and $43.9 \%$ for NCMS (Yip et al. 2012). Pension benefits also vary substantially across different schemes. For instance, when NRPS was introduced in 2009, rural elders aged over 60 without prior

\footnotetext{
11 The basic pension payout is mainly financed by central government. In some provinces, the monthly basic pension could be higher than 55 RMB if local government provides higher subsidies. For example, the monthly basic pension in Beijing was $280 \mathrm{RMB}$ in its first year (Cheng et al. 2015b).

${ }^{12}$ Urban Resident Basic Medical Insurance was launched in 2007 and coverage rate approached 92.9\% in 2010 (Yip et al. 2012). Urban Resident Pension System was newly introduced in 2011.
} 
contributions were only entitled to a basic pension of $55 \mathrm{RMB}$ per month. The amount was half of China's poverty threshold set in 2010, and about $15 \%$ of the per capita consumption level for rural population. ${ }^{13}$ By contrast, the average pension benefit for UEPS pensioners reached 1,349 RMB per month in $2010 .{ }^{14}$

A series of reforms in public education, health care and pension programs mentioned above are anchored in providing equitable access and in reducing social stratification. It is unclear, however, whether their gendered implications received adequate attention. ${ }^{15}$ These changes in public transfer programs and in gender relations form the context of our examination of gendered implications of public transfer programs, to which we turn below.

\section{Analytical Approach and Data Sources}

To understand and analyze the benefit incidence of public transfers by gender and age, we adopt the National Transfer Accounts method (NTA, Lee and Mason 2011). The NTA method, which has been widely applied in over 40 countries, captures a fundamental feature of contemporary societies: the economic lifecycle. At working ages, people produce more than they consume; while at young and old ages, they consume more than they could earn through labor, thus generating a lifecycle deficit. Essentially, the national transfer flow account is based on the following identity.

$$
C(x)-Y^{l}(x)=\tau(x)+Y^{A}(x)-S(x)
$$

The lifecycle deficit at age $x$, or the excess of consumption $C(x)$ over labor income $Y^{l}(x)$, can only be financed through two economic mechanisms: net transfers $\tau(x)$ and asset-based reallocations, which equals to asset income $Y^{A}(x)$ net of savings $S(x)$. The equation holds at both per capita and aggregate levels. Except for labor income, economic flows can be further disaggregated by sector, such as separating transfers by private versus public transfers.

We focus in this study on three major types of public transfers, transfers for

\footnotetext{
132010 poverty threshold was set at 1274 RMB per year The monthly average per capita consumption of rural household was 365 RMB in 2010 (China Statistical Yearbook 2011).

${ }^{14}$ The annual outlay of UEPS in 2010 reached 941 billion RMB and the number of retirees covered by UEPS was 58.1 million. It is estimated that the average monthly pension benefit under UEPS was 1349 RMB per retiree. (China Labor Statistical Year Book 2014)

${ }^{15}$ Compulsory education is an exception. For compulsory education, there is a strong gender component, with all levels of government emphasizing gender equity in access to primary and lower middle schools in China.
} 
education, health care and pension, to fill up the gap between consumption and labor income. These transfers not only affect gender inequality, but also exhibit generational imbalances. For instance, the government mainly provides schooling to children, pensions to the elderly, and health care to everyone, but more so to the elderly.

NTA estimation utilizes both macro-level and micro-level data to construct cross-sectional age profiles for a single year. Macro data from the System of National Accounts, or government administrative records and financial statistics, are used to estimate economy-wide aggregates, such as government spending on education, health care and pension. Micro data, obtained from the 2010 wave of China Family Panel Studies (CFPS), are used to estimate age-specific per capita economic flows. CFPS, a nationally representative household survey, has been conducted once every two years since 2010. The survey questionnaire consists of intergraded modules for rural and urban respondents, and the survey gathers rich information on household structure, employment and marriage history, income and expenditures, and social security benefits, among others (Xie 2014). The 2010 survey, covering 25 out of 31 provinces in China, interviewed 14,798 households with a sample of 42,681 household members. As shown in Table 1, the female subsample of CFPS is slightly older than the male sub-sample, due to imbalanced sex ratio at young ages and also to longer female life expectancy.

[Table 1 about here]

Our estimation procedure contains three steps, largely mirroring the method adopted by Turra et al. (2011) for their study of Brazil and Chile. First, we divide CFPS sample by gender and estimate age-specific per capita values for males and females respectively. Age-specific per capita public education transfer is obtained by combining public spending per student for each level of education from government administrative records, with age- and level-specific public school enrollment rate estimated from the CFPS sample. ${ }^{16}$ Age profile of public pension transfer is constructed from survey responses on pension benefits received in the previous year. ${ }^{17}$

\footnotetext{
16 At each age, per capita public spending for each level of schooling is calculated as level-specific public cost per student times the level-specific public school enrollment rate. Subsequently, age-specific public spending is calculated by summing across the levels of schooling (pre-primary school, primary school, middle school, ordinary senior high school, vocational high school, vocational college, academic college, adult college and postgraduate education), because adolescents at a certain age are likely to be enrolled in difference levels of education, such as vocational high school and ordinary high schools.

17 CFPS questionnaire includes both individual pension benefits and household pension income received in the year prior to the survey. However, the variable on individual pension benefits contains a high proportion
} 
Estimating age profile of public health care transfers is more complicated and more subject to error (Mason and Lee 2011). Public transfers for health care in NTA consist of two parts: health care purchased by individuals and reimbursed through public health insurance programs, and health care directly provided by public clinics and hospitals (United Nations Population Division 2013). Age-specific health consumption reimbursed through public programs can be constructed by subtracting out-of-pocket medical expenses from actual medical expenses by age based on the CFPS sample. ${ }^{18}$ Government-provided health care should be allocated to individuals using administrative records such as patient information or utilization of inpatient and outpatient care by age as proxies. However, such data are unavailable from CFPS or administrative records. Instead, we construct the age profile of out-of-pocket medical expenditures from the CFPS data to substitute for public health care utilization, based on the assumption that medical expenditures are proportional to utilization rates. These two age profiles combined generate the age profile of public health care transfers.

The second step in our estimation is to smooth age profiles. Most age profiles are smoothed using local regression to reduce noises except for education, because age profiles of public education transfers contain many discontinuities, which are not random but are the product of specific ages of entering and leaving schools (United Nations Population Division 2013).

The last step is to adjust the smoothed age profiles (non-smoothed for education) proportionately to match the aggregate total for each type of public transfers. National aggregate total, from government financial statistics, is then divided between men and women. Aggregate public transfers at each age for men (or women) are calculated as per capita values times the size of male (or female) population at each age. Aggregate public transfers for men (or women) summed across ages are then compared with corresponding aggregate totals for men (or women), and finally the original smoothed age profiles are adjusted upwards or downwards.

of missing values as only those who retire from formal sectors have answered the question. Hence, we equally allocate household pension income to elders qualified for pension within the household.

18 CFPS child questionnaire (for children aged 0-15) provides information on reimbursed medical expenses for each child (total medical expenses net of out-of-pocket expenses). CFPS adult questionnaire only has information on reimbursed hospitalization expenses but not on reimbursed outpatient expenses. 


\section{Gender Inequalities in Benefiting from Public Transfers}

\subsection{Public Education Transfers}

Our investigation starts at examining age distributions of public education transfers by gender. In general, education transfers are evenly distributed among boys and girls on a per capita basis, as shown in Figure 4. Due to the active enforcement of free compulsory education, male and female enrolment rates in primary and junior high schools reached virtually $100 \%$ by 2010 . While senior high school education is not yet compulsory, the progression rate from junior high schools to senior high schools also doubled from $42.8 \%$ in 2000 to $82.5 \%$ in $2010 .{ }^{19}$ The peak of public educational transfers occurs at around age 14, resulting from both universal enrollment and high public cost per student at the stage of junior high school education. $^{20}$

Of particular importance is that females receive almost the same transfers as males at the tertiary education level. Tertiary education in China is a dual system, consisting of three-year vocational colleges (zhuanke) and four-year academic colleges (benke). Overall, female enrollment in tertiary education surpasses that of men in the CFPS sample, but women have a slightly lower enrollment in academic colleges and a higher enrollment in vocational colleges than men, the same pattern as documented by Yeung (2013) using another national household survey in 2008. Public education cost per vocational college student is only about one half of the cost per academic college student. This accounts for the very modest gender difference in transfers at ages 18-22, even with an overall higher female enrollment at the tertiary level.

A number of factors contribute to the emerging gender parity in education in China. The proportion of quota in social sciences and humanities has increased after college expansion, which tends to favor female students (Yeung 2013). In addition, college admission has been shifting from primarily merit-based in the planned economy to exam-oriented in the market economy (Li et al. 2012, Yeung 2013). Girls are found to outperform boys throughout primary and middle schools (Lai 2010), and

\footnotetext{
${ }^{19}$ Data source: China Statistical Brief 2014.

${ }^{20}$ Public education cost per junior high school student in China was about $30 \%$ higher than that per primary school student, 13\% higher than that per regular (academic) senior high school student in 2010 (China Education Statistical Yearbook 2011).
} 
thus they have increasing competitiveness in college entrance examinations. Such a pattern is also observed in the United States, South Korea and other settings in recent years (Buchmann and Diprete 2006, Goldin et al. 2006, Shavit et al. 2007). Last but not the least, three-decade long enforcement of the one-child policy has resulted in an unintended outcome. Being the only girl in the family removes the potential competition from another child, especially a boy, for resources, and thus the gender gap between parental investment in boy's and girl's education has significantly narrowed (Fong 2002, Lee 2012, Tsui and Rich 2002, Veeck et al. 2003), or even reversed to favor girls (Cheng and Zhang 2015).

[Figure 4 about here]

Aggregate public education transfers by age are calculated using per capita values to multiple the population size by age. Figure 5 presents the age distribution of male and female population based on 2010 census and Figure 6 shows the gender differential in public education transfers at the aggregate level. At young ages, boys receive a larger share of education transfers than girls, because sex ratio at birth has escalated since the enforcement of one-child policy in the early 1980s. There is an evident bulge at age 20 for both men and women on the aggregate profiles, due to a larger cohort size as revealed in Figure 5. As China's total fertility rate hit the replacement level (2.1 children per couple) in 1990 and has experienced a sustained decline, the cohort aged 20 in 2010 is larger than any younger cohorts who were born after 1990.

[Figure 5 about here]

[Figure 6 about here]

\subsection{Public Health Care Transfers}

Age profile of per capita pubic health care transfers exhibits a $\mathrm{J}$-shaped curve for both males and females, as shown in Figure 7, and they resemble the age pattern of mortality rate in China. At one end of the lifecycle, transfers are high below age 10, particularly at infanthood. At the other end, health care transfers rise after age 50. An average person aged 75 receives transfers nearly twice as high as that received by an average 50-year-old person. Such a pattern is also observed in developed countries and some developing countries such as Brazil and Chile (Tung 2011, Turra et al. 2011). 
Gender differential in public transfers for health care is noticeable at both ends of the lifecycle. In infanthood and childhood, health care transfers are biased against girls, partially due to a traditional son preference in China (Choe et al. 1995). Unlike compulsory education, public health care is neither compulsory nor free even if the child is insured. Researchers have found that girls from non-single-child families, mostly in rural areas with a stronger son preference, are significantly disadvantaged (Choe et al. 1995, Ren et al. 2014), and may get reduced access to public health care. $^{21}$

Gender gap in health care transfers widens over age 60. For instance, public transfers to male elders aged 70 reach 1,440 RMB on average, 52 percent higher than the amounts transferred to their female peers. This is largely resulting from increased disparity in entitlement to health insurance programs among older cohorts. As introduced in the second section, health insurance eligibility is tied to an individual's residence and past employment status (Strauss et al. 2012). As shown in Figure 1, male labor force participation has been consistently higher than that of female at prime working ages over the past two decades. In 1990, 35\% of employed men aged $40-49$, who reached the age of 60 and over by 2010 , were in non-farming sectors, as compared with only $24 \%$ of employed women. ${ }^{22}$ Such a gender gap in employment sector persisted in 2010 (Figure 2). Among workers in non-farming sectors, older men were much more likely to hold a position in state enterprises or government prior to retirement. This leads to higher chances among men to participate in UEBMI, which covers a wider range of outpatient services and offers lower deductibles and co-payments, especially for retirees than those in URBMI and NCMS. ${ }^{23}$ In particular, elders are found to have more elastic demand for health care than working age adults (Cheng et al. 2015a, Ringel et al. 2002). The more generous health insurance package

\footnotetext{
${ }^{21}$ China's birth control policy is differentiated between urban and rural areas. In 19 provinces, a "1.5-children policy" is adopted in rural areas, allowing couples to have a second child if the first child is a girl. In 5 provinces, two-children policy is applied in rural areas. Urban couples of Han ethnicity are all required to follow a strict one-child policy (Gu et al. 2007).

22 Data source: 1990 census.

${ }^{23}$ UEBMI reimburses both inpatient and outpatient services, while URBMI and NCMS adopted in a majority of cities/counties only reimburse inpatient services and outpatient services for catastrophic diseases (Lei and Lin 2009). The deductibles are also much lower and reimbursement rates are higher for retirees as compared to current employees under UEBMI. For example, under UEBMI in Shanghai, the deductible of outpatient service for the retirees ranges from 300 to 700 RMB depending on the age of retirees, while it is uniformly 1,500 RMB for current workers. The deductible of inpatient service ranges from 700 to 1,200 RMB for retirees, as compared with 1,500 RMB for current workers. The reimbursement rate of inpatient service is $92 \%$ for retirees and $85 \%$ for the current workers. The reimbursement rate of outpatient service could reach a high of $90 \%$ for retirees, while it does not exceed $70 \%$ for current workers.
} 
not only induces higher reimbursement through public insurance program, but also effectively encourages the elders to seek more public health care.

[Figure 7 about here]

As a result of gender differentials in receiving public transfers in health care over the ages, aggregate health care spending for males is about 12 percent higher than that for females. In Figure 8, we present the comparison of public health care transfers by gender, weighted by population age distribution. China's abnormal sex ratio at birth in recent decades further exacerbates the gender differential at young ages. By contrast, gender gap over age 60 is ameliorated, resulting from a longer female life expectancy and consequently a larger proportion of women surviving into old ages.

[Figure 8 about here]

\subsection{Public Pension Transfers}

Gender differential in public pension transfers at the per capita level is most pronounced among the three types of transfers we examine in this study. This is particularly the case above age 75 , as shown in Figure 9. Similar to health care transfers, women's disadvantage in pension benefits can be traced to their employment histories. As noted earlier, a larger proportion of female elders were previously employed in agriculture, in informal sectors or unemployed with no entitlement to public pensions before $2009 .^{24}$ Even under the urban employee pension scheme or civil servants pension scheme, gender gap in pre-retirement earnings and occupational rankings also leads to differentiated pension benefits. A similarly wide gender gap in pension income is also observed in the UK and Japan, a legacy of past employment norms and pension policies, though it is an issue that remains largely ignored by policymakers (Gin and MacIntyre 2013, Takayama 2014).

There are also several interesting contrasts between men and women in pension transfers. As shown in Figure 9, first, pension benefits for women aged in the late 50s are higher than those for men, a reflection of earlier withdrawal from the labor market for urban females. As noted, urban female workers legally retire and are entitled to pension at the age of 50 or 55, while urban male workers need to wait until the age of 60. Second, pension benefits for men increase substantially over age. For instance, average annual pension benefits are 2,662 RMB for men aged 60, and it doubles by

\footnotetext{
${ }^{24}$ New Rural Pension System was initiated in 2009 and Urban Resident Pension System was launched in 2011.
} 
the age of 78. In a stark contrast, pension benefits received by women rise much more slowly over age and even decline at very senior ages, due to both the lower coverage and lower benefits per beneficiary among the oldest-old women. As China's 2010 census reports, only one fifth of women aged 80 cited public pensions as their major financial source, in contrast to nearly $40 \%$ among men aged 80 .

[Figure 9 about here]

When combined with population age structure, a somewhat different gender profile emerges. In terms of aggregate pension benefits, both age profiles peak at around age 60 and then decline over age. Despite the noticeable difference in per capita pension benefits, aggregate pension spending is almost equal for men and women at ages above 60 . Such a pattern is due to the fact that women outlive men, even though women have lower per capita pension benefits.

[Figure 10 about here]

\section{Discussions and Conclusion}

This study contributes to the international comparative research on gender inequality in economic welfare, with a particular perspective on gender gap in benefiting from public transfers over the lifecycle. It also adds empirical evidence on the gendered implications of recent public transfer reforms in China, which have yet to receive much attention to our knowledge. Within the framework of National Transfer Accounts, we find mixed results of gender inequality in three major types of public transfers. Males and females equally benefit from public education transfers, with females even surpassing males in college enrollment in recent years. This is in sharp contrast to only twenty years ago, when women lagged far behind men in progressing to high schools, let alone to colleges (Bauer et al. 1992). Health care transfers are evenly distributed between men and women in adulthood, but biased against females in infanthood and at senior ages. Similarly, older men enjoy higher pension benefits than women, and the gender gap widens most notably at the very advanced ages.

With these three types of public transfers combined, we see a gender pattern of receiving public transfers that is both familiar and new. As shown in Figure 11, on one hand, it is familiar in the sense that as expected, gender gap remains substantial at 
ages above 60. Male elders aged 80 and over receive an annual public transfer worth 7,855 RMB per capita, about 52\% higher than that for females. The root of male advantage at old ages lies in their educational, occupational and earning privileges prior to retirement age, as well as in the fragmented design of health care and pension programs. While the Chinese government has strived to expand health insurance and pension coverage among disadvantaged groups (the rural and the unemployed) over the past decade, the stark disparity in generosity across different schemes and the link between entitlement and residence and employment history both exacerbate the gender inequality in health care utilization and in economic well-being.

On the other hand, the gender pattern also reveals some new and encouraging signs. In particular, female youths are catching up and are receiving the same public transfers as males. Active enforcement of free compulsory education (exemption of tuition and free textbooks) has ensured all boys and girls access to public primary schools and junior high schools, and equally benefit from receiving public education support. Furthermore, the college expansion policy enacted since 1999 has allowed a significantly larger number of youths to attain tertiary education, especially females. In China, a tertiary education is a golden ticket for rural youth to gain an urban hukou status and for holding a professional, managerial or government position (Yueng 2013). The returns to education for females are found to be higher than those for males (Ren and Miller 2012a, Ren and Miller 2012b, Wang 2013). Hence, gender-balanced public spending on education, especially on tertiary education, might contribute to reducing gender gaps in labor market outcomes, and also in the entitlement to health insurance and pension benefits at later ages in the future. However, we should not be overly optimistic about the implications of gender parity in schooling. Evertsson et al. (2009) for instance have shown that gender inequalities in labor force participation, work hours, and occupational segregation have not diminished in the United States, the Netherlands and Sweden, all countries that have long reached near gender equality in schooling. For example, in the United States and the Netherlands, females who complete less than high schools are in the labor force about 60 percent as much as male counterparts; this figure rises to about 80 percent for the college educated group.

[Figure 11 about here]

Overall, while gender inequality persists or even deteriorates in some arenas 
since China's market-oriented reforms, the gender-neutral pattern of public transfers for the young cohorts documented in this study and a gradual unification of social security system may offer promising signs for improved gender equality in the future. Recently, China's State Council has announced a goal to build a fair, unified and standardized pension system for its whole population before 2020. Following many years of delay, China took a firm step forward in 2014. Forty million civil servants can no longer count on a defined-benefit pension program with a high replacement rate, financed out of the general fiscal revenue. They are required to contribute $8 \%$ of their monthly salary into the state pension fund, and their pension payouts now depend on the length of employment, the amount of contribution, and the comparison of pre-retirement salary with local urban average wage. The revised pension scheme for civil servants resembles the program for urban enterprise workers. Such a policy shift helps integrate the fragmented system and thus narrow the gender gap in pension benefits, which is particularly pronounced among the current old cohorts.

Our study, while presenting abundant evidences on benefit incidences of public transfers by gender, should be interpreted with caution. First, both our data and the NTA method require a variety of assumptions in the calculations. Accordingly, the results should be taken as indicative rather than definitive. For example, the calculation of public education spending is based on the assumption that unit cost within each level of education does not vary by gender. Coupled with universal enrollment in compulsory education, this assumption leads to a finding that public education transfers are evenly distributed among boys and girls at compulsory education stage. With persistent son preference, families might be more likely to send boys to prestigious public primary and junior high schools with a higher unit cost. Such gender disparity, however, cannot be captured in this study. Second, public transfers for health care are determined by both supply and demand factors. Male elders are found to receive more health care transfers than female peers, but it is unclear whether this is due to their higher demand for medical services. Even though older women enjoy higher chances of survival, they are a vulnerable group with higher risks of cognitive impairment and functional disability (Zeng et al. 2003, Zhang 2006). Hence, if female elderly have a stronger demand than males, then the actual gender inequality in health care transfers is even more severe than revealed in this paper. Third, this paper only investigates the inflows of public transfers while it 
does not take into account of outflows, such as taxes and social security contributions. Male elderly receive more pension benefits and health care transfers at present, but they have also paid higher taxes and premiums when they were working. In that sense, the higher benefits received by male elderly are, to some extent, a delayed remuneration for their contributions in the past. However, we might defend our estimate by the fact the contributory component of urban enterprise employee pension was not introduced until 1997, and of civil servants pension was newly launched in 2014, thus the current older cohorts are largely beneficiaries of a pay-as-you-go system. Last but not the least, this paper reveals a gender neutral pattern in public education and health spending for adolescents, while without knowing whether private education and health spending is lopsided in favor of males. So it will be misleading to conclude that China has reached gender equality in education and health.

As noted, gender stratification persists in all societies and complete gender equality is not achieved overnight. With growing advantage in female educational attainment and a gradual unification of social security system, China could expect to have a narrowing gender gap in the coming years, at least in benefiting from public transfers. 


\section{Reference cited}

Bauer, John, Feng Wang, Nancy E. Riley, and Xiaohua Zhao (1992). "Gender inequality in urban China: Education and employment." Modern China, 18 (3): 333-370.

Borrell, Carme, Laia Palencia, Carles Muntaner, Marcelo Urquia, Davide Malmusi, and Patricia O'Campo (2014). "Influence of macrosocial policies on women's health and gender inequalities in health." Epidemiologic Reviews, 36: 31-48.

Branisa, Boris and Stephan Klasen (2013). "Gender inequality in social institutions and gendered development outcomes." World Development, 45: 252-268.

Buchmann, Claudia and Thomas A. DiPrete (2006). "The growing female advantage in college completion: the role of family background and academic achievement." American Sociological Review, 71 (4): 515-541.

Cai, Yong (2013). “ China's new demographic reality: Learning from the 2010 census.” Population and Development Review, 39(3): 371-96.

Castro-Leal, Florencia, Julia Dayton, Lionel Demery, and Kalpana Mehra (1999). "Public social spending in Africa: Do the poor benefit?" The World Bank Research Observer, 14 (1): 49-72.

Chang, Chin-fen and Paula England (2011). "Gender inequality in earnings in industrialized East Asia." Social Science Research, 40: 1-14.

Cheng, Lingguo, Hong Liu, Ye Zhang, Ke Shen, and Yi Zeng (2015a). "The impact of health insurance on health outcomes and spending of the elderly: Evidences from China's New Cooperative Medical Scheme.” Health Economics, 24 (6): 672-691.

Cheng, Lingguo, Hong Liu, Ye Zhang, and Zhong Zhao (2015b). "The heterogeneous impact of pension income on elderly living arrangements: Evidence from China's new rural pension scheme.” IZA Discussion Papers, No. 9116.

Cheng, Yuan and Lei Zhang (2015). "Public education spending and private substitution in urban China." Journal of Development Economics, 115: 124-139.

Choe, Minja K., Hongsheng Hao, and Wang Feng (1995). "The effect of gender and other factors on child survival in China." Social Biology, 42 (1-2): 50-64.

Chu, Junhong (2001). "Prenatal sex determination and sex-selective abortion in rural Central China." Population and Development Review, 27 (2): 259-281.

Coale, Ansley J. and Judith Banister (1994). "Five decades of missing females in 
China." Demography, 31 (3): 459-479.

Cohen, Philip N. and Feng Wang (2009). "Market and gender pay equity: have Chinese reforms narrowed the gap?" In Deborah Davis and Feng Wang (Eds.) Creating Wealth and Poverty in Postsocialist China. Stanford, California: Stanford University Press.

Croll, Elisabeth J. (1983). Chinese Women since Mao. Longdon, UK: Zed Books.

Earles, Kimberly (2013). “The gendered consequences of the European Union's pensions policy." Women's Studies International Forum, 38: 75-82.

Evertsson, Marie, Paula England, Irma Mooi-Reci, Joan Hermsen, Jeanne de Bruijn and David CotterIs (2009). Gender Inequality Greater at Lower or Higher Educational Levels? Common Patterns in the Netherlands, Sweden, and the United States. Social Politics, 16 (2): 210-241.

Farrer, James (2014). "Love, sex, and commitment: Delinking premarital intimacy from marriage in urban China.” In Deborah S. Davis and Sara L. Friedman (Eds.) Wives, Husbands, and Lovers: Marriage and Sexuality in Hong Kong, Taiwan, and Urban China. Palo Alto: Stanford University Press.

Folbre, Nancy and Douglas Wolf (2012). "The intergenerational welfare state." Population and Development Review, S38: 36-51.

Fong, Vanessa L. (2002). "China's one-child policy and the empowerment of urban daughters." American Anthropologist, 104 (4): 1098-1109.

Ginn, Jay and Ken MacIntyre (2013). "UK pension reform: Is gender still an issue?" Social Policy \& Society, 12 (1): 901-103.

Goldin, Claudia, Lawrence F. Katz, and Ilyana Kuziemko (2006). "The homecoming of American college women: The reversal of the college gender gap." Journal of Economic Perspective, 20(4): 133-156.

Gu, Baochang, Feng Wang, Zhigang Guo, and Erli Zhang (2007). "China's local and national fertility policies at the end of the Twentieth century." Population and Development Review, 33 (1): 129-147.

Honig, Emily and Gail Hershatter (1988). Personal Voices: Chinese women in the 1980's. Stanford, CA: Stanford University Press.

Hull, Terence H. (1990). "Recent trends in sex ratios at birth in China." Population and Development Review, 16: 63-83.

Klasen, Stephan and Francesca Lamanna (2009). "The impact of gender inequality in 
education and employment on economic growth in developing countries: Updates and extensions." Feminist Economics, 15 (3): 91-132.

Kotlikoff, Laurence J. and Scott Burns (2012). The Clash of Generations: Saving Ourselves, Our Kids, and Our Economy. Cambridge MA: MIT Press.

Lai, Fang (2010). "Are boys left behind? The evolution of the gender achievement gap in Beijing's middle schools." Economics of Education Review, 29 (3): 383-399.

Lei, Xiaoyan and Wanchuan Lin (2009). "The New Cooperative Medical Scheme in rural China: does more coverage mean more service and better health?" Health Economics, 18 (S2): 25-46.

Lee, Ming-Hsuan (2012). "The one-child policy and gender equality in education in China: evidence from household data." Journal of Family and Economic Issues, $33(1): 41-52$.

Lee, Ronald and Andrew Mason (2011). "Theoretical aspects of national transfer accounts." In R. Lee and A. Mason (Eds.) Population Aging and the Generational Economy: A Global Perspective, Cheltenham, UK and Northampton, MA: Edward Elgar.

Li, Chunling and Shi Li (2008). "Rising gender income gap and its dynamics in China: Market competitions or sex discrimination.” Sociological Studies, 2: 94-117. (In Chinese)

Li, Hongbin, Pak Wai Liu, and Junsen Zhang (2012). "Estimating returns to education using twins in urban China.” Journal of Development Economics, 97: 494-504.

Lin, Wanchuan, Gordon G. Liu, and Gang Chen (2009). “The urban resident basic medical insurance: a landmark reform towards universal coverage in China." Health Economics, 18: S83-S96.

Liu, Hong and Zhong Zhao (2014). "Does health insurance matter? Evidence from China's urban resident basic medical insurance." Journal of Comparative Economics, 42 (4): 1007-1020.

Mason, Andrew and Ronald Lee (2011). "Introducing age into national accounts" in in R. Lee and A. Mason (Eds.) Population Aging and the Generational Economy: A Global Perspective, Cheltenham, UK and Northampton, MA, Edward Elgar.

Otis, Eileen M. (2009). "Labor of luxury: gender and generational inequality in a Beijing hotel." In Deborah Davis and Feng Wang (Eds.) Creating Wealth and 
Poverty in Postsocialist China. Stanford, California: Stanford University Press.

Parish, William L., Edward O. Laumann, and Sanyu A. Mojola (2007). "Sexual behavior in China: Trends and comparisons." Population and Development Review, 33 (4): 729-756.

Peng, Xizhe and Juan Huang (1999). "Chinese traditional medicine and abnormal sex ratio at birth in China." Journal of Biosocial Science, 31 (4): 487-503.

Pozen, Robert C. (2013). Tackling the Chinese Pension System. Paulson Policy Memorandum.

Qi, Liangshu and Xiaoyuan Dong (2015). “Unpaid care work's interference with paid work and the gender earnings gap in China." Feminist Economics, DOI: 10.1080/13545701.2015.1025803.

Ren, Weiwei, Anu Rammohan and Yanrui Wu (2014). "Is there a gender gap in child nutritional outcomes in rural China?" China Economic Review, 31: 145-155.

Ren, Weiwei and Paul W. Miller (2012a). "Changes over time in the return to education in urban China: Conventional and ORU estimates." China Economic Review, 23 (1): 154-169.

Ren, Weiwei and Paul W. Miller (2012b). "Gender differentials in the payoff to schooling in rural China.” Journal of Development Studies, 48 (1): 130-150.

Ringel Jeanne S., Susan D. Hosek, Ben A. Vollaard, and Sergej Mahnovski (2002). "The elasticity of demand for health care; a review of the literature and its application to the military health system." Available from: http://www.rand.org/pubs/monograph_reports/MR1355.html

Sen, Amartya (1999). Development as Freedom. New York, NY: Alfred A. Knopf.

Shavit, Yossi, Richard Arum, and Adam Gamoran (2007). Stratification in Higher Education: a Comparative Study. Stanford: Stanford University Press.

Shen, Ce and John B. Williamson (2010). "China's new rural pension scheme: Can it be improved?" International Journal of Sociology and Social Policy, 30 (5/6): 239-250.

Shu, Xiaoling and Yanjie Bian (2003). "Market transition and gender gap in earnings in urban China." Social Forces, 81 (4): 1107-1145.

Strauss, John, Hao Hong, Xiaoyan Lei, Ling Li, Alber Park, Li Yang, and Yaohui Zhao (2012). "Health care and insurance among the elderly in China: Evidence from the CHARLS pilot," in P. Smith and M. Majmundar (Eds.) Aging in Asia: 
Findings from New and Emerging Data Initiatives, Washington, DC: National Academies Press.

Takayama, Noriyuki (2014). "Intergenerational equity and the gender gap in pension issues.” In Benedict J. Clements, Frank Eich, and Sanjeev Gupta (Eds.) Equitable and Sustainable Pensions: Challenges and Experience. Washington, D.C.: International Monetary Fund.

Treiman, Donald J. (2013). "Trends in educational attainment in China," Chinese Sociological Review, 45 (3): 3-25.

Tsui, Ming and Lynne Rich (2002). "The only child and educational opportunity for girls in urban China." Gender and Society, 16(1): 74-92.

Tung, An-Chi (2011). "Consumption over the lifecycle: an international comparison." In R. Lee and A. Mason (Eds.) Population Aging and the Generational Economy: A Global Perspective, Cheltenham, UK and Northampton, MA: Edward Elgar.

Turra, Cassio M., Mauricio Holz, and Daniel Cotlear (2011). "Who benefits from public transfers? Incidence across income groups and across generations in Brazil and Chile. " In Daniel Cotlear (ed.) Population Aging: Is Latin America Ready? Washington, D.C., the World Bank.

United Nations Population Division (2013). National Transfer Accounts Manual: Measuring and Analyzing the Generational Economy. New York.

Veeck, Ann, Laura Flurry, and Naihua Jiang (2003). "Equal dreams: The one child policy and the consumption of education in urban China." Consumption Markets and Culture, 6 (1): 81-94.

Wagstaff, Adam, Magnus Lindelow, Jun Gao, Ling Xu, and Juncheng Qian (2009). "Extending health insurance to the rural population: an impact evaluation of China's new cooperative medical scheme." Journal of Health Economics, 28 (1): $1-19$.

Wang, Feng (2008). Boundaries and Categories: Rising Income Inequality in Post-socialist Urban China. Palo Alto: Stanford University Press.

Wang, Feng (2011). "The future of a demographic overachiever: long-term implications of the demographic transition in China." Population and Development Review, S37: 173-190.

Wang, Le (2013). "How does education affect the earnings distribution in urban China?" Oxford Bulletin of Economics and Statistics, 75 (3): 435-454. 
Whyte, Martin K. (1984). "Sexual inequality under socialism: the Chinese case in perspective." In James L. Watson (ed.) Class and Social Stratification in Post-Revolutionary China. Cambridge: Cambridge University Press.

$\mathrm{Wu}$, Xiaogang (2010). "Economic transition, school expansion and educational inequality in China, 1990-2000.” Research in Social Stratification and Mobility, 28: 91-108.

Xie, Yu (2014). "An introduction to the China Family Panel Studies (CFPS)." Chinese Sociological Review, 47 (1): 3-29.

Yao, Xianguo and Lan Tan (2005). "Family income and labor force participation of married women in urban China." Economic Research Journal, 5: 18-27. (In Chinese)

Yeung, Wei-Jun Jean (2013). "Higher education expansion and social stratification in China." Chinese Sociological Review, 45 (4): 54-80.

Yip, Winnie Chi-Man, William C. Hsiao, Wei Chen, Shanlian Hu, Jin Ma, and Alan Maynard (2012). "Early appraisal of China's huge and complex health care reforms." The Lancet, 379 (9818): 833-842.

Zeng, Yi, Ping Tu, Baochang Gu, Yi Xu, Bohua Li, and Yongping Li (1993). "Causes and implications of the recent increase in the reported sex ratio at birth in China." Population and Development Review, 19 (2): 283-302.

Zeng, Yi, Yuzhi Liu, and Linda K. George (2003). "Gender differentials of the oldest old in China." Research on Aging, 25 (1): 65-80.

Zhang, Zhenmei (2006). "Gender differentials in cognitive impairment and decline of the oldest old in China." The Journals of Gerontology Series B: Psychol Sci Soc Sci, 61 (2): S107-S115. 


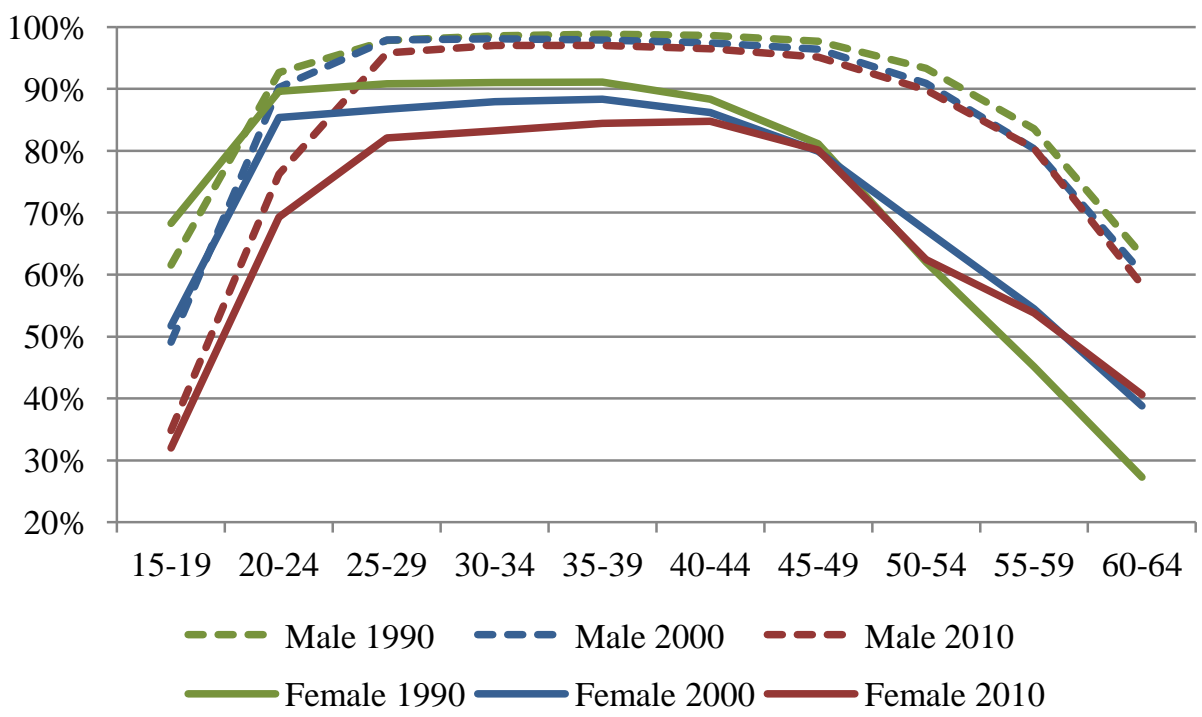

Figure 1 Labor force participation rate by gender and age, China, 1990-2010 Source: Authors' calculations based on data from 1990, 2000, 2010 censuses. 


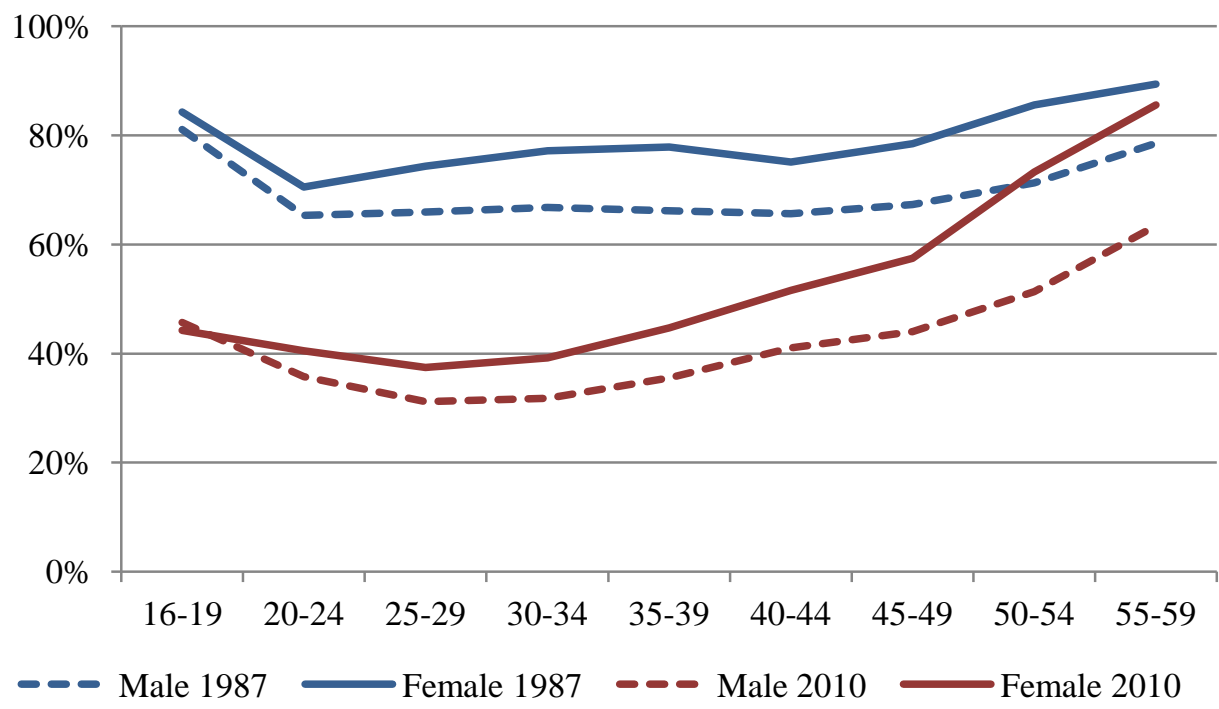

Figure 2 Share of labor force in farming by gender and age, China, 1987 and 2010 Source: Authors' calculations based on data from China Statistical Yearbook 1987 and 2010 census. 


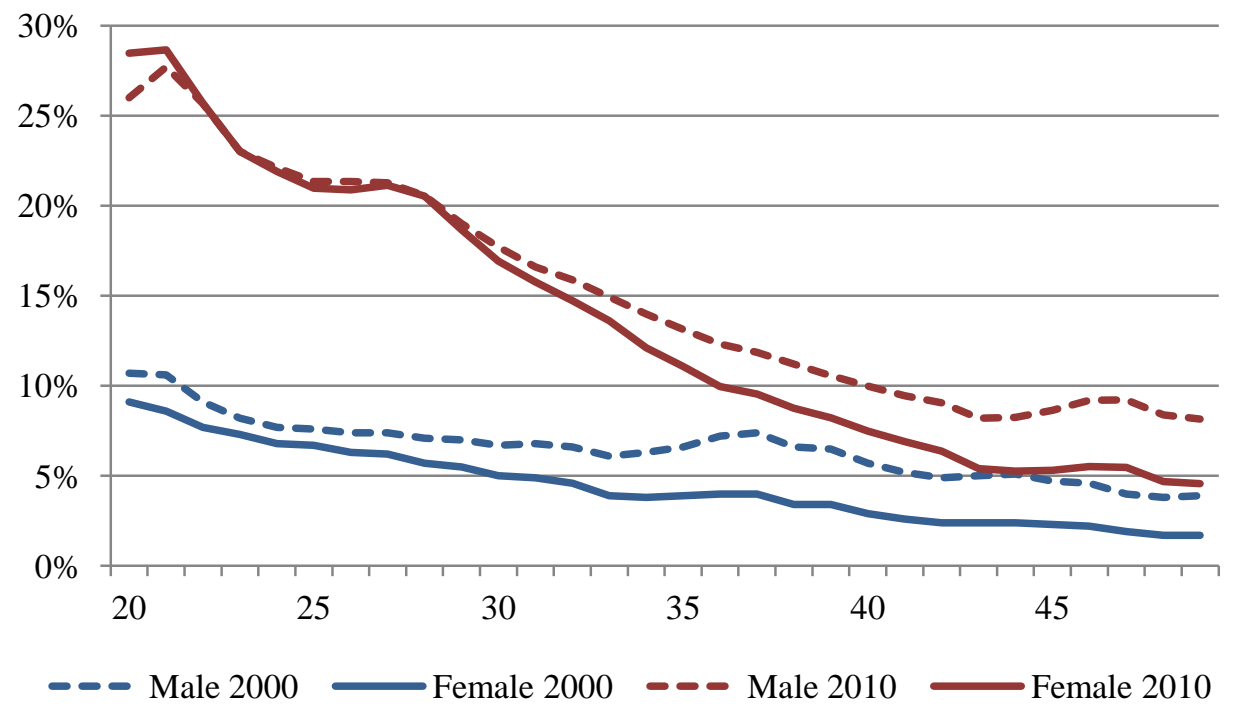

Figure 3 Share of population with college education by gender and age, China, 2000 and 2010

Source: Authors' calculations based on data from 2000 and 2010 censuses. 


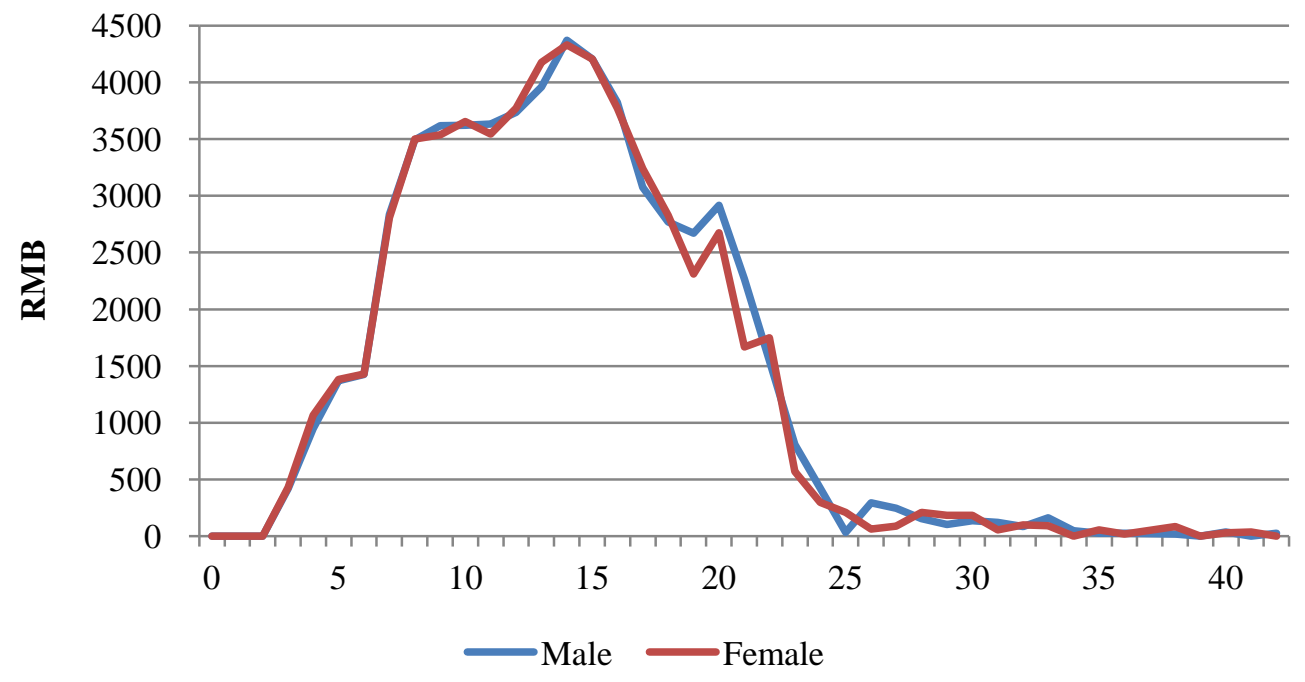

Figure 4 Per capita public education transfers by gender and age, China, 2010 Source: Authors' calculations based on data from 2010 wave of China Family Panel Studies and government statistics. 


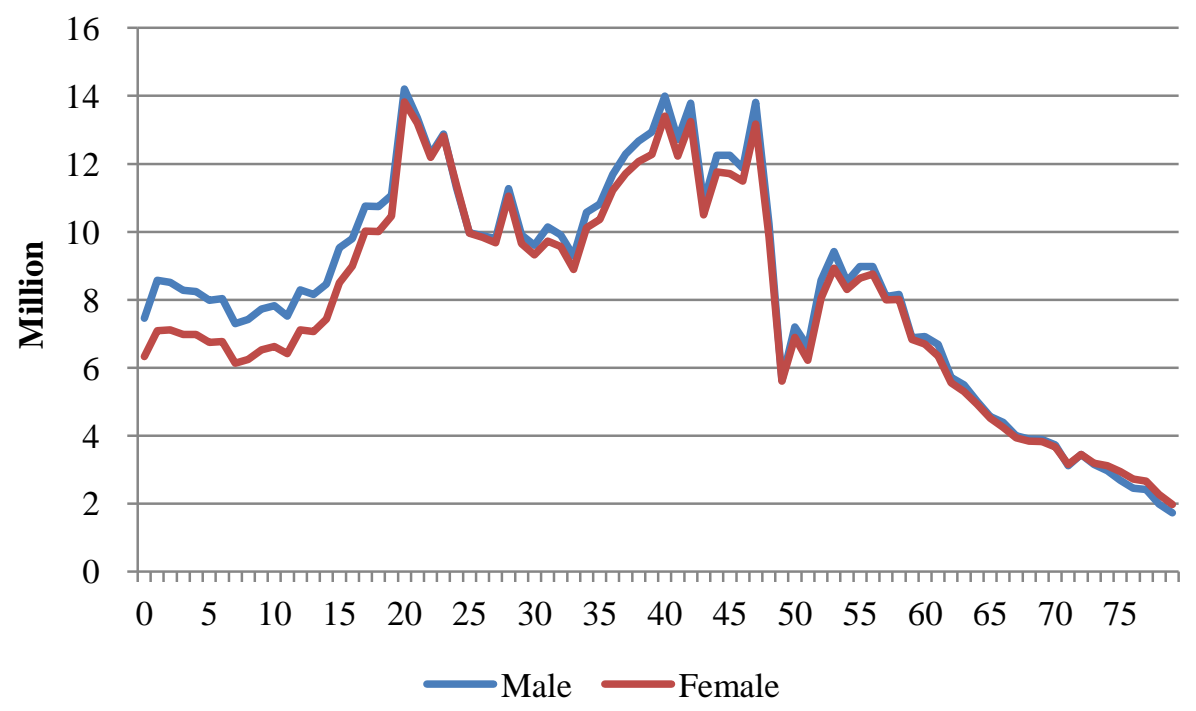

Figure 5 Population size by gender and age, China, 2010 Source: 2010 census. 


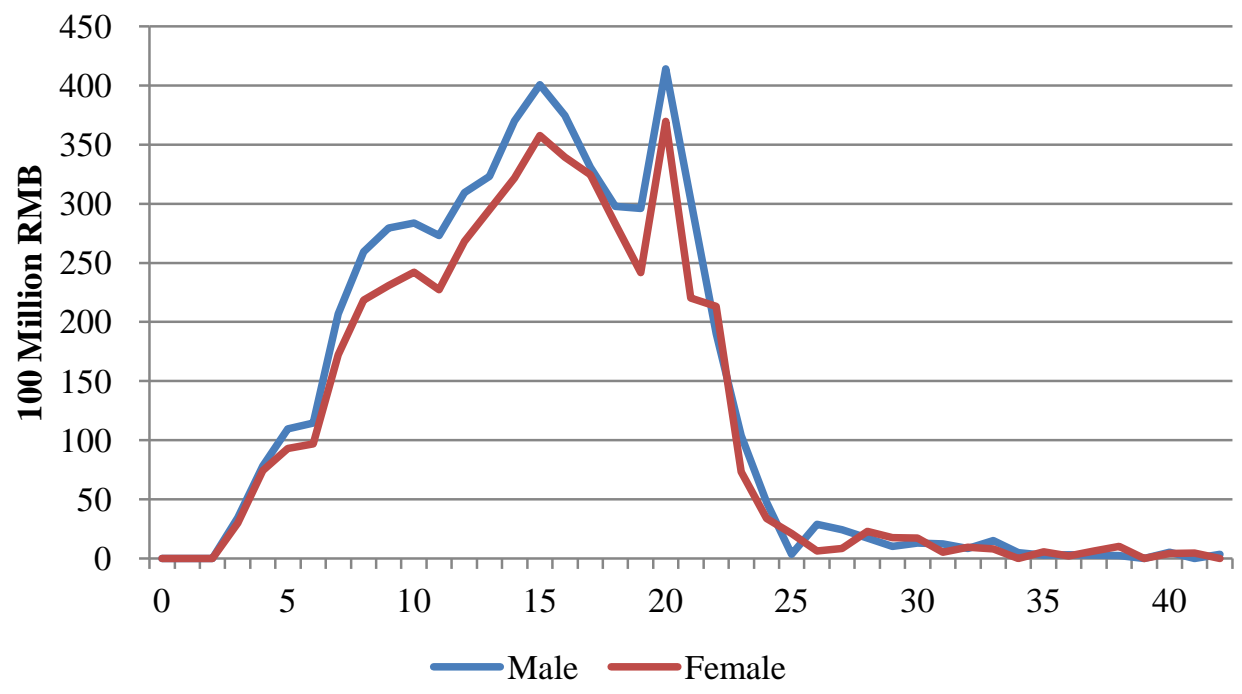

Figure 6 Aggregate public education transfers by gender and age, China, 2010 Source: same as Figure 4. 


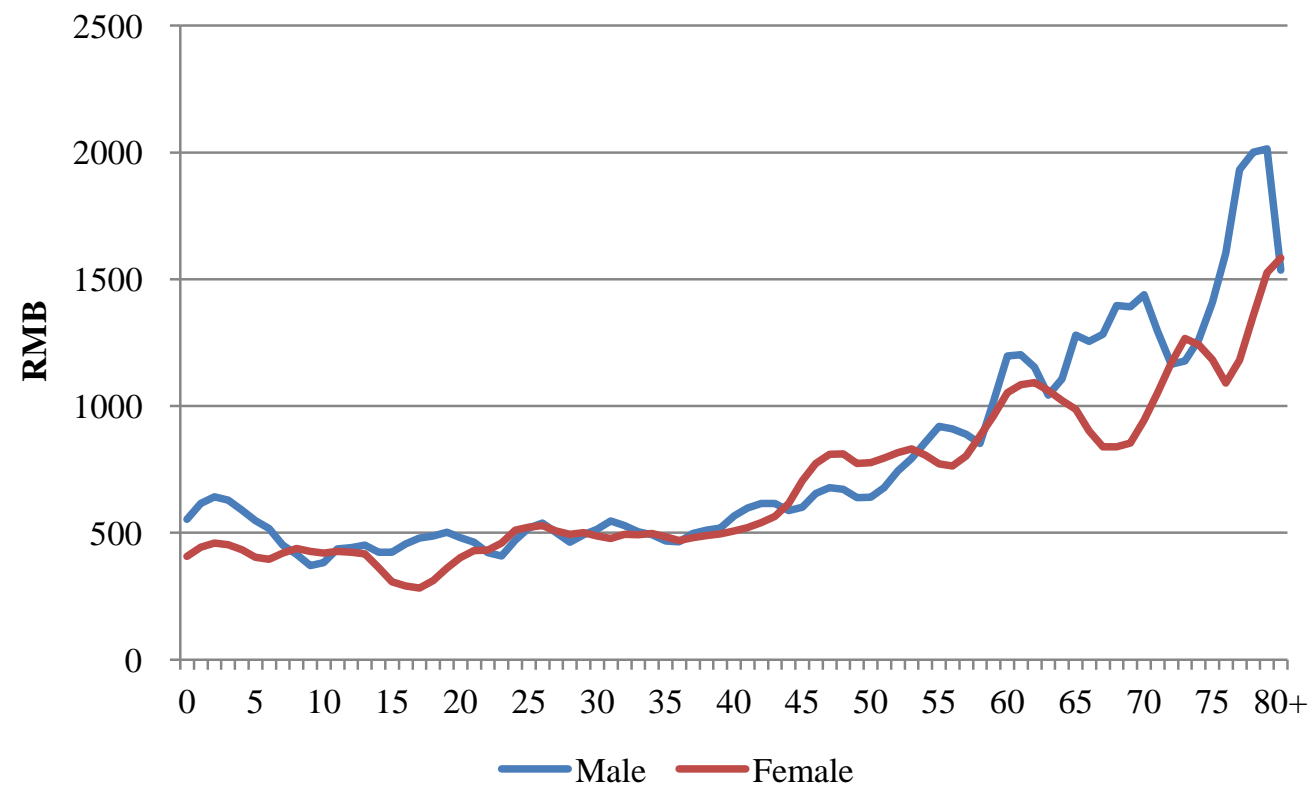

Figure 7 Per capita public health care transfers by gender and age, China, 2010 Source: same as Figure 4. 


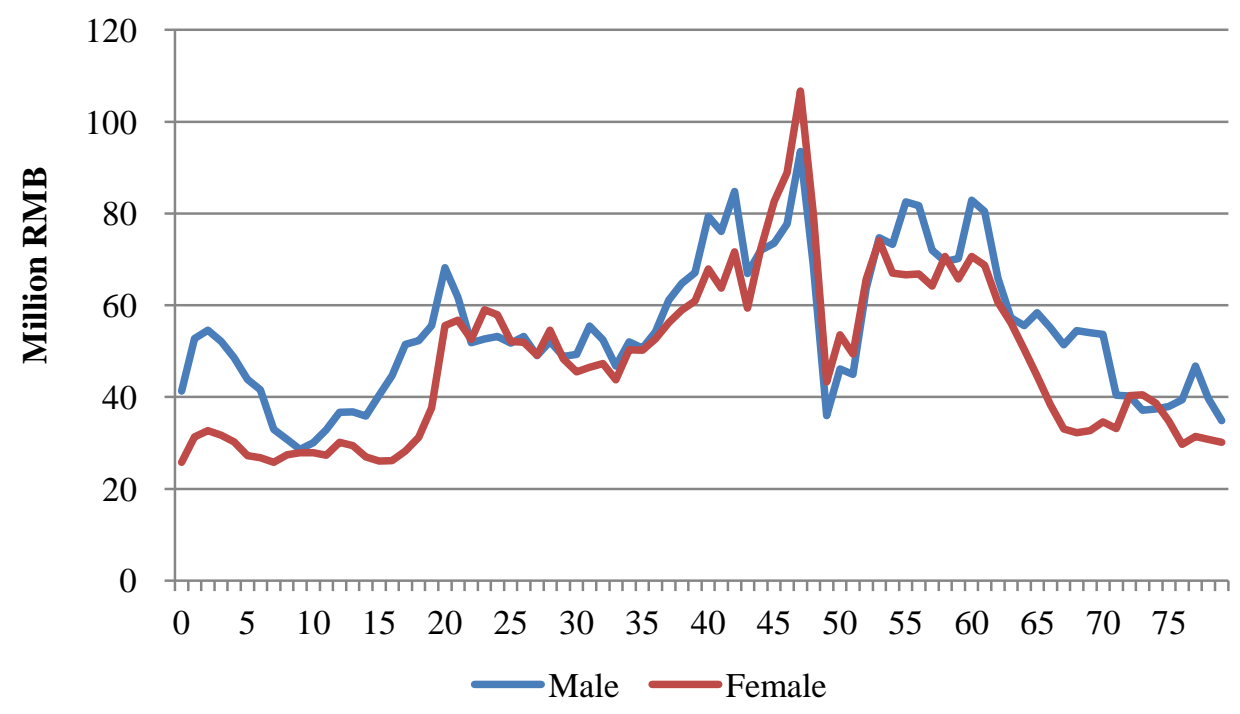

Figure 8 Aggregate public health care transfers by gender and age, China, 2010 Source: same as Figure 4. 


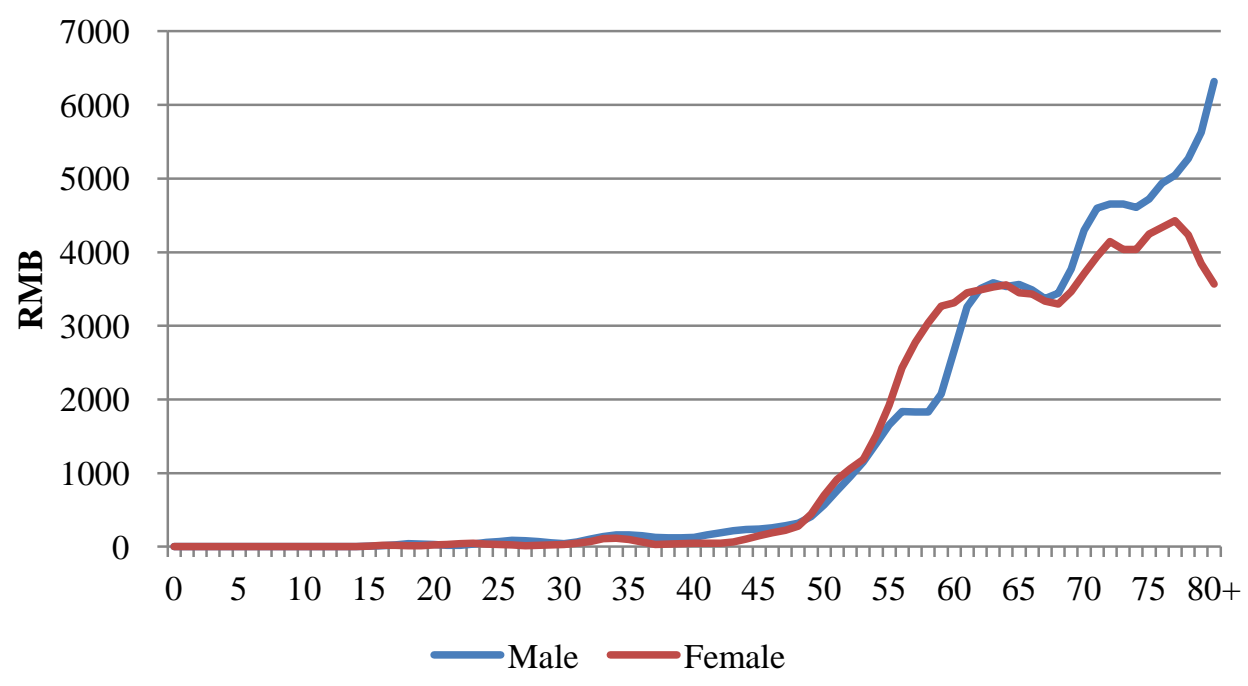

Figure 9 Per capita public pension transfers by gender and age, China, 2010 Source: same as Figure 4. 


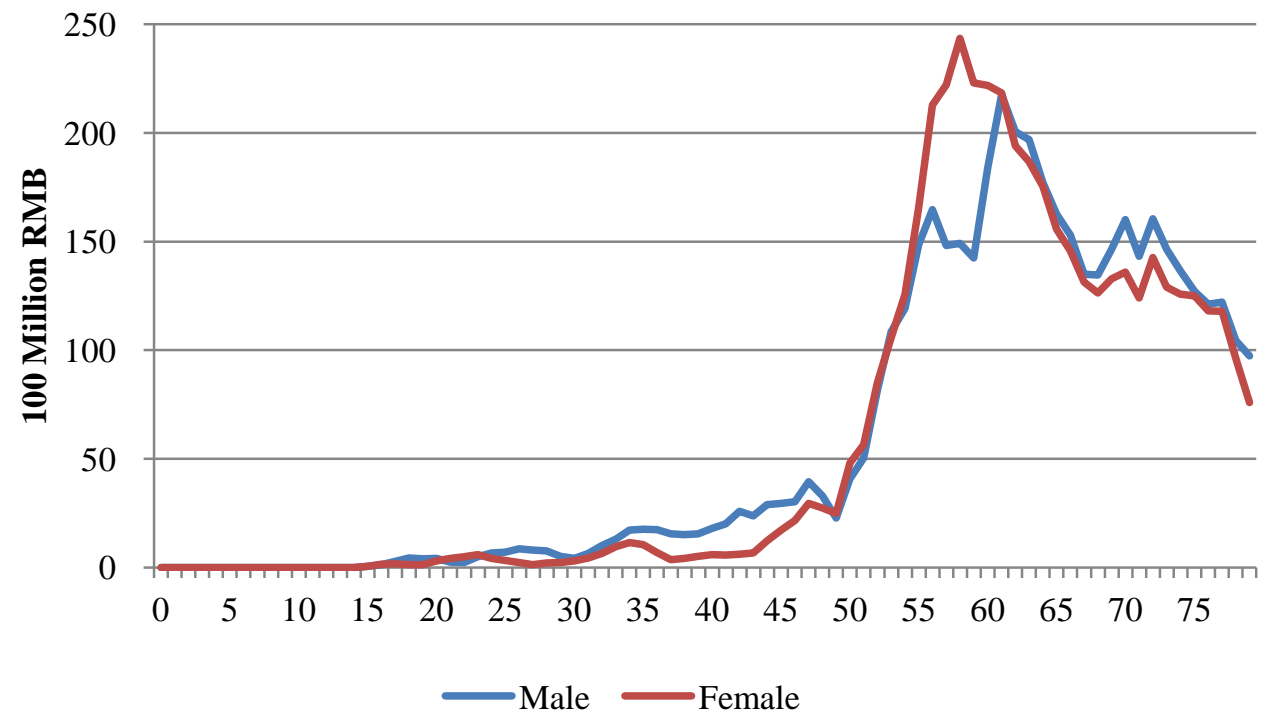

Figure 10 Aggregate public pension transfers by gender and age, China, 2010 Source: same as Figure 4. 


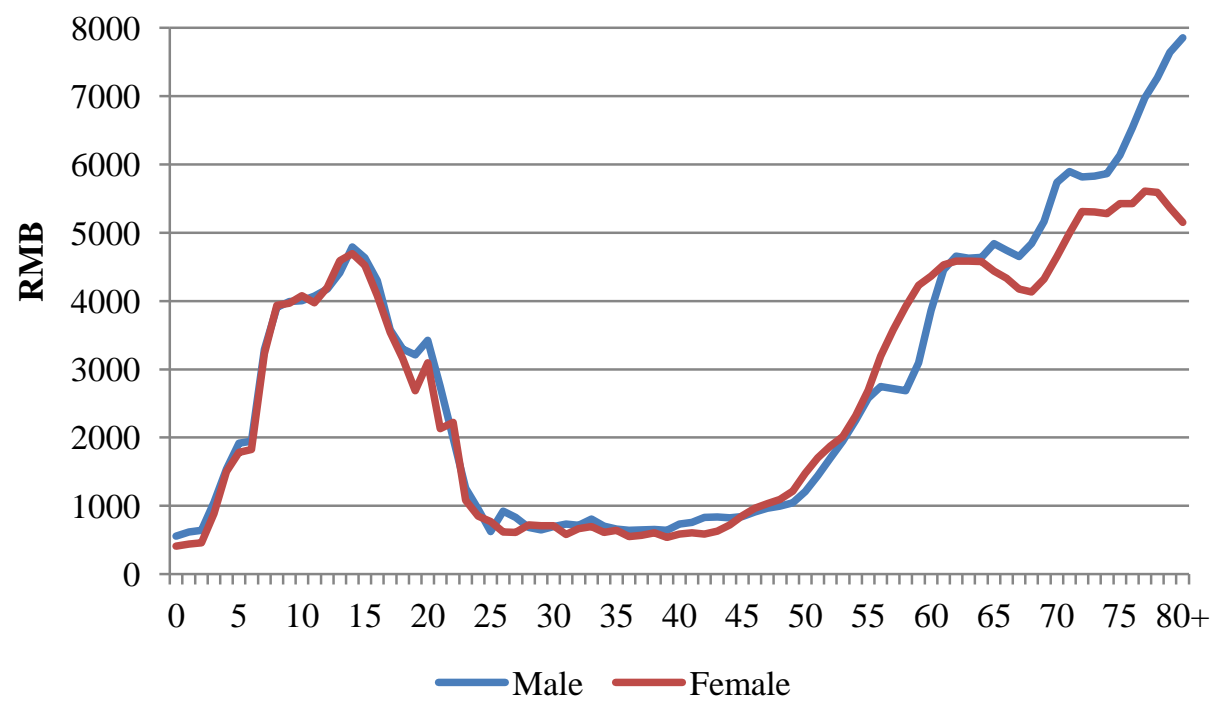

Figure 11 Per capita total public transfers by gender and age, China, 2010 Source: same as Figure 4. 
Table 1 CFPS sample distribution by gender and age group

\begin{tabular}{lccc}
\hline Age group & Male & Female & Total \\
\hline $0-15$ & 4736 & 4224 & 8960 \\
& $(22.6 \%)$ & $(19.4 \%)$ & $(21.0 \%)$ \\
$16-64$ & 13943 & 15080 & 29023 \\
& $(66.5 \%)$ & $(69.4 \%)$ & $(68.0 \%)$ \\
$65+$ & 2282 & 2416 & 4698 \\
& $(10.9 \%)$ & $(11.1 \%)$ & $(11.0 \%)$ \\
\hline
\end{tabular}

Note: Percent distribution in parentheses. 